\title{
Anticorpos anti-Toxoplasma gondii em suínos criados em granjas de elevado e baixo padrão sanitário no noroeste do Paraná
}

\author{
Anti-Toxoplasma gondii antibodies in pigs raised on farms with \\ high and low sanitary standards in the Northwest of Parana
}

Ronaldo César da Rosa ${ }^{[a]}$, Rodrigo José Mattei ${ }^{[a]}$, Rodrigo Costa da Silva ${ }^{[b]}$, Luis Sérgio Merlini[c] , Helio Langoni ${ }^{[b]}$, Aristeu Vieira da Silva ${ }^{[d]}$

[a] Acadêmicos do curso de graduação em Medicina Veterinária, Universidade Paranaense (UNIPAR), bolsistas do Programa Institucional de Bolsas de Iniciação Científica (PIBIC/UNIPAR), Umuarama, PR - Brasil.

[b] Médico-Veterinário, doutor, Núcleo de Pesquisa em Zoonoses (NUPEZO), Faculdade de Medicina Veterinária e Zootecnia,Universidade Estadual de São Paulo (UNESP), Botucatu, SP - Brasil.

[c] Médico-Veterinário, doutor, professor do curso de graduação em Medicina Veterinária, Universidade Paranaense (UNIPAR), Umuarama, PR - Brasil.

[d] Médico-Veterinário, doutor, Departamento de Ciências Biológicas, Universidade Estadual de Feira de Santana (UEFS), Feira de Santana, BA - Brasil, e-mail: aristeuvsilva@gmail.com

\section{Resumo}

O objetivo do presente estudo foi verificar os índices percentuais da presença de anticorpos anti-Toxoplasma gondii em amostras de soro de matrizes suínas em granjas de baixo padrão sanitário, bem como em animais encaminhados ao abate procedentes de granjas de elevado padrão sanitário. A toxoplasmose em suínos é importante em virtude da ocorrência de problemas reprodutivos nessa espécie, com grande potencial de agravo para a saúde pública, uma vez que a carne de animais infectados pode representar risco de infecção para o ser humano. No período de fevereiro a novembro de 2008 foram coletadas 353 amostras de sangue de suínos, sendo 94 de matrizes de granjas de baixa tecnificação em Umuarama (PR) e 259 de animais abatidos em Iporã (PR), oriundos de granjas de alto padrão sanitário. A frequência de anticorpos anti-Toxoplasma gondii foi verificada pelo método de aglutinação direta (MAD) e comparada entre as duas classes de animais pelo Teste Exato de Fischer. Foram encontrados 28,7\% e 1,7\% de animais positivos nas granjas e no abatedouro, respectivamente. Concluiu-se que há baixa prevalência de anticorpos anti-Toxoplasma gondii em animais de granjas dotadas de elevado padrão sanitário encaminhados ao abate, e que a infecção em propriedades de baixa tecnificação é elevada, podendo constituir-se em risco à saúde pública.

Palavras-chave: Toxoplasma gondii. Suíno. Diagnóstico. Epidemiologia.

\section{Abstract}

The objective of the present study was to verify the presence of anti-Toxoplasma gondii antibodies in sows from farms with high and low sanitary standards. Toxoplasmosis is an important issue in hog production as it can cause 
reproductive disorders in these species; it also poses as threat to public health, since meat from infected animals represents a risk of infection for humans. From February to November 2008, 353 pig blood samples were collected: 94 from sows of farms with low sanitary standards in Umuarama (PR) and 259 from animals of an abattoir in Iporã (PR), originated from farms with high sanitary status. Frequency of anti-Toxoplasma gondii antibodies was verified by modified agglutination test (MAT), and compared between the two classes of animals by the Fischer's Exact Test. Results found that $28.7 \%$ and $1.1 \%$ of the animals were antibody-positive in Umuarama and Ipero, respectively, representing a significant difference between these groups. In conclusion, there was a low prevalence of animals that were positive to anti-Toxoplasma gondii in farms with good sanitary conditions, whereas farms with lower sanitary standards presented a high level of contamination, which can constitute a risk for public health.

Keywords: Toxoplasma gondii. Swine. Diagnosis. Epidemiology.

\section{Introdução}

A toxoplasmose é causada pelo protozoário Toxoplasma gondii, parasito intracelular obrigatório com ciclo biológico complexo, acometendo praticamente todas as espécies animais homeotérmicas (MILLAR et al., 2008).

Uma importante via de transmissão para o ser humano é a ingestão de cistos teciduais, presentes na musculatura de animais infectados, e que não são visualizados à linha de inspeção (MOURA et al., 2007). A grande importância do estudo da prevalência da infecção pelo Toxoplasma gondii em suínos é que, dentre os animais de produção, essa espécie é considerada a fonte mais importante de infecção para o ser humano (DA SILVA et al., 2008).

Movido por essa preocupação, o presente estudo objetivou avaliar a presença de anticorpos anti-Toxoplasma gondii em amostras de soro de matrizes suínas em granjas de baixo padrão sanitário, bem como em animais encaminhados ao abate procedentes de granjas de elevado padrão sanitário.

\section{Materiais e métodos}

Foram coletadas 353 amostras de sangue de suínos, sendo 94 de matrizes oriundas de pequenas propriedades do município de Umuarama (PR) e 259 de um abatedouro do município de Iporã (PR), animais com idades entre cinco e seis meses.

Nas propriedades rurais os animais foram contidos por meio do uso de cachimbo. 0 sangue foi então colhido da veia auricular ou jugular em tubos de ensaio de $10 \mathrm{~mL}$. No caso do abatedouro, a coleta ocorreu após a dessensibilização dos animais, no momento da sangria, e, em seguida, o sangue foi acondicionado em tubos de ensaio.

Todas as amostras foram encaminhadas ao Laboratório de Medicina Veterinária Preventiva e Saúde Pública da Universidade Paranaense (UNIPAR). Então, as amostras foram centrifugadas e o soro armazenado em microtubos de $1,5 \mathrm{ml}$, que foram acondicionados a $-20{ }^{\circ} \mathrm{C}$ até o momento da realização do método de aglutinação direta (MAD), segundo Desmonts e Remington (1980), em diluição do soro a 1:25.

A frequência de animais reagentes em granjas e no abatedouro foi comparada pelo Teste Exato de Fischer, considerando-se significativo valor de $P$ menor que 0,05 .

\section{Resultados}

Dentre os 353 soros submetidos ao teste, 28 $(7,9 \%)$ foram reagentes. Das 94 amostras coletadas em propriedades rurais, $27(28,7 \%)$ foram positivas para a presença de anticorpos anti-Toxoplasma gondii. Entre as 259 amostras oriundas do abatedouro foi detectado o anticorpo em $0,4 \%$ delas $(1 / 259)$. Comparando-se os dois resultados, verificou-se diferença significativa $(\mathrm{p}<0,05)$, com odds-ratio de 107,82 para o encontro de matrizes positivas em relação aos animais de abatedouro.

\section{Discussão}

A análise dos dados permitiu verificar que dois fatores podem ter concorrido para a diferença 
encontrada na taxa de positivos para os anticorpos anti-Toxoplasma gondii entre os animais coletados no abatedouro e os animais coletados diretamente nas propriedades rurais. 0 primeiro fator é a diferença de idade dos animais. Animais mais velhos, neste caso as matrizes, têm maior chance de exposição às fontes de infecção do que animais jovens, como já relatado por Tsutsui et al. (2003) e Caporali et al. (2005). Além disso, nos sistemas de criação com menor nível de tecnificação, os animais têm maior possibilidade de entrarem em contato com fontes de infecção do que os de elevado nível de tecnificação. Os resultados obtidos por Caporali et al. (2005) no Estado de São Paulo e por Da Silva et al. (2008), em estudo realizado na mesma região da presente pesquisa, no ano de 2007, fundamentam a afirmação anterior.

Os resultados oriundos do abatedouro deste estudo estão em concordância com os resultados de Carletti et al. (2005), que demonstraram a cifra de 2,6\% de animais positivos entre os 395 avaliados provenientes de 13 abatedouros de várias regiões do Paraná. Os autores também sinalizaram a tendência do decréscimo de prevalência da toxoplasmose nesta espécie em função da tecnificação das criações. Moura et al. (2007) encontraram uma prevalência relativamente baixa $(8,5 \%)$ em animais abatidos na região de Guarapuava (PR). Entretanto, no trabalho de Millar et al. (2008), foram encontrados $25,5 \%$ de animais positivos entre os 408 abatidos, oriundos de 25 municípios da região sudoeste do Paraná. Esta é uma região contígua onde foram verificadas as matrizes do presente trabalho e dos relatos de Carletti et al. (2005). Portanto, chama a atenção o fato de que as características regionais das criações suinícolas podem contribuir fortemente para a elevação das taxas de infecção. Concluiu-se que existe baixa prevalência de anticorpos anti-Toxoplasma gondii em animais encaminhados ao abate, cuja procedência seja de granjas dotadas de elevado padrão sanitário e que a infecção em propriedades de baixa tecnificação é elevada, podendo constituir-se em risco à saúde pública.

\section{Agradecimentos}

Os autores agradecem à Fundação Araucária de Apoio ao Desenvolvimento Científico e Tecnológico do Paraná pelo financiamento do projeto de pes- quisa (Convênio 147/2006, Protocolo n. 8866) e à Universidade Paranaense pelo financiamento do projeto de pesquisa (Protocolo n. 12324/2008) e concessão de bolsas de Iniciação Científica.

\section{Referências}

CAPORALI, E. H. G. et al. Comparação de métodos para determinação da prevalência de anticorpos anti-Toxoplasma gondii em suínos dos Estados de São Paulo e Pernambuco Brasil. Arquivos de Ciências Veterinárias e Zoologia da UNIPAR, v. 8, n. 1, p. 19-24, 2005.

CARLETTI, R. T. et al. Prevalência da infecção por Toxoplasma gondii em suínos abatidos no Estado do Paraná, Brasil. Semina: Ciências Agrárias, v. 26, n. 4, p. 563-568, 2005.

DA SILVA, A. V. et al. Ocorrência de anticorpos AntiToxoplasma gondii em suínos da região Oeste do Paraná, Brasil. Veterinária e Zootecnia, v. 15, n. 2, p. 263-266, 2008.

DESMONTS, G.; REMINGTON, J. S. Direct agglutination test for diagnosis of Toxoplasma infection: method for increasing sensitivity and specificity. Journal of Clinical Microbiology, v. 11, n. 6, p. 562-568, 1980.

MILLAR, P. R. et al. Toxoplasma gondii: estudo soro-epidemiológico de suínos da região Sudoeste do Estado do Paraná. Pesquisa Veterinária Brasileira, v. 28, n. 1, p. 1518, 2008.

MOURA, A. B. et al. Ocorrência de anticorpos contra Toxoplasma gondii em suínos e ovinos abatidos no município de Guarapuava, PR, Brasil. Revista Brasileira de Parasitologia Veterinária, v. 16, n. 1, p. 54-56, 2007.

TSUTSUI, V. S. et al. Soroepidemiologia e fatores associados à transmissão do Toxoplasma gondii em suínos no norte do Paraná. Archives of Veterinary Science, v. 8, n. 2, p. 27-34, 2003.

Recebido: 16/12/2010

Received: $12 / 16 / 2011$

Aprovado: 21/09/2011

Approved: 09/21/2011 